\title{
The Dynamic Behavior of the Flow in the Pipeline with 0il
}

\author{
Jana Jablonská
}

VŠB-Technical University of Ostrava, Faculty of Mechanical Engineering, Department of Hydromechanics and Hydraulic Equipment, Czech Republic

Abstract: The article deals with dynamic flow behaviour in oil piping, modulus of fluid elasticity and its influence on the dynamic behaviour of hydraulic systems. In this paper, a methodology is to model the unsteady flow. Mathematical modeling of the measured pressures is implemented on the basis of the boundary conditions and is carried out in program Matlab SimHydraulics. The comparison results are in agreement.

Keywords: hydraulic hammer, simulation, unsteady flow, modulus of fluid elasticity, oil.

\section{Introduction}

Mathematical - physical modeling is based on the application of the laws of physics. They can be used to create mathematical models of mechanical, hydraulic, pneumatic, electrical and thermal systems. The simulation is consisted in creating a simulation mathematical model and its solution.

\section{Hydraulic fluid elastic modulus}

The modulus of elasticity has a very important role in the calculations and affects the dynamics of hydraulic systems. It depends on pressure, temperature and the amount of dissolved air. The amount of air in the oil has the greatest impact on value of the modulus of elasticity, as the air is much more compressible. Its theoretical value for mineral oil is in the range of $K=(1.4-1.8) \cdot 10^{9} \mathrm{~Pa}[7,8]$. Measurement of modulus of elasticity is poorly realizable especially in operating conditions, so its value is determined laboratory or estimated. In this work, the modulus of elasticity is determined from the wavelength and consequently by the sound velocity in the hydraulic hammer. However, this modulus of elasticity is determined as time independent of pressure. This affects the accuracy of the calculation. [3, 5, 9]

\section{The dynamics of the two-stage indirect-controlled valve}

Reducing two-stage indirectly controlled valve has a pressure control function in the circuit - the safety valve. Generally, these valves are used to reduce higher pressures $p$ and flow rates $Q$. Its scheme is shown in Fig. 1.

Equations describing the dynamics of the reducing valve are given by the following relations. The valve is closed at $x=x_{m}$ and fully opened at $x=0$. At the node with pressure $p_{2}$ the following linearized equations apply

$$
\begin{aligned}
& Q_{5}=Q_{3}+Q_{4} \\
& Q_{3}=\frac{\left(p-p_{2}\right)}{R_{1}} \\
& Q_{4}=Q_{2}=S v=S \frac{d x}{d t} \\
& Q_{5}=\frac{\left(p_{2}-p_{r}\right)}{R_{2}}
\end{aligned}
$$




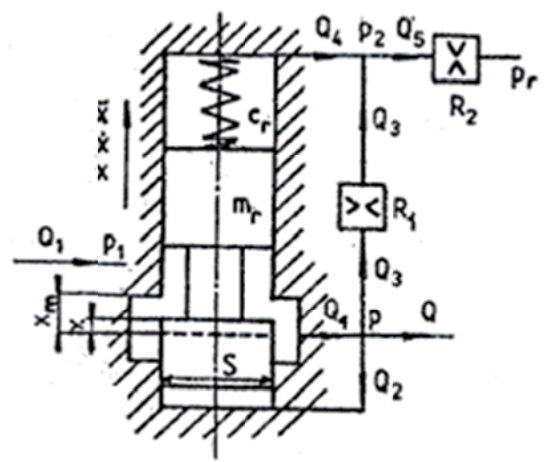

Fig. 1: Diagram reducing indirectly controlled valve ( $p$ - pressures, $Q$ - flow rates, $R$ - resistive). [2]

The motion equation of the valve spool is [2]

$m_{r} \frac{d^{2} x}{d t^{2}}+\left(b_{r} S^{2} \frac{R_{1} \cdot R_{2}}{R_{1}+R_{2}}\right) \frac{d x}{d t}+c_{r} x=$

$=\left(p-p_{1}\right) S \frac{R_{1}}{R_{1}+R_{2}}$

Where $m_{r}$ - mass of the spool valve, $b_{r}$ damping coefficient, $c_{r}$ spring constant, $S$ surface of the spool valve.

In Matlab SimHydraulics, a differential equation of the first order is used, so equation (2) is divided by the mass of the spool valve and the first member (second derivative) is not considered in the equation. The equation after this mathematical adjustment has the following shape

$$
\frac{\left(b_{r} S^{2} \frac{R_{1} R_{2}}{R_{1}+R_{2}}\right)}{m_{r}} \frac{d x}{d t}+\frac{c_{r} x}{m_{r}}=\frac{\left(p-p_{1}\right) S}{m_{r}} \frac{R_{1}}{R_{1}+R_{2}}
$$

The equations can be solved numerically for labeled flows and displacement $x$ at the given pressure. The necessary constants are determined from the experimental measurements of transient characteristics [2].

\section{Mathematical modeling}

The modeling of hydraulic circuit elements consists in assembling mathematical models to allow computation of pressure and flow values at individual points in the circuit. The method of electrical analogy of hydraulic resistances is used for definition of mathematical models of hydraulic elements An electrohydraulic analogy allows the examination of hydraulic elements, their groups and systems by investigation methods applied on electrical circuits whose transient properties are comparable [2]. Based on the analogy of hydraulic parameters $(p, Q)$ and electrical parameters $(U, i)$ the resistances are defined [2-4]:

Hydraulic resistance to motion represents friction and local resistances in flowing fluid

$$
R=\frac{d(\Delta p)}{d Q}
$$

Hydraulic resistance to acceleration (hydraulic inductance) from the mechanical point of view, it is the influence of mass inertia. The reason of resistance to acceleration is inertia of the fluid or inertia of a moving mass (piston, piston rod, spring, etc.). [2].

$L=\frac{\Delta p}{\frac{d Q}{d t}}$

Hydraulic capacity represents the inverse value of resistance to deformation (fluid, gas, pipes, springs, etc.) [2].

$$
C=\frac{Q}{\frac{d(\Delta p)}{d t}}
$$

\section{Hydraulic hammer measurement}

Fig. 2 shows the circuits on which the hydraulic hammer measurements have been made. In variant $A$ there is displayed the circuit with a toothed flowmeter located between the valves. The toothed flowmeter represents a local resistance in the hydraulics circuit, therefore it has been replaced by clamp-on flowmeter, see version B. In the hydraulics circuit the hydraulic oil VG 46 at the temperature $26^{\circ} \mathrm{C}$ flows.

Hydro-generator HG1 pumps the liquid from the main tank $\mathrm{T} 1$ to the circuit and it is powered by electric motor M1. The circuit is protected against overload by the safety valve SV (two-stage indirectly controlled reducing valve). On the tank $\mathrm{T} 1$ is placed measuring cube $\mathrm{MC}$, on which the pressure $p_{t}$ is measured. The toothed flowmeter TFM is located between ball valves BV1 and BV2 (variant A). Behind the flowmeter there is a T-piece with parallel connected nozzle and a closed ball valve. Tested horizontal pipeline is connected between valves YV1 and YV2 with the circuit. These valves are electrically controlled and equipped 


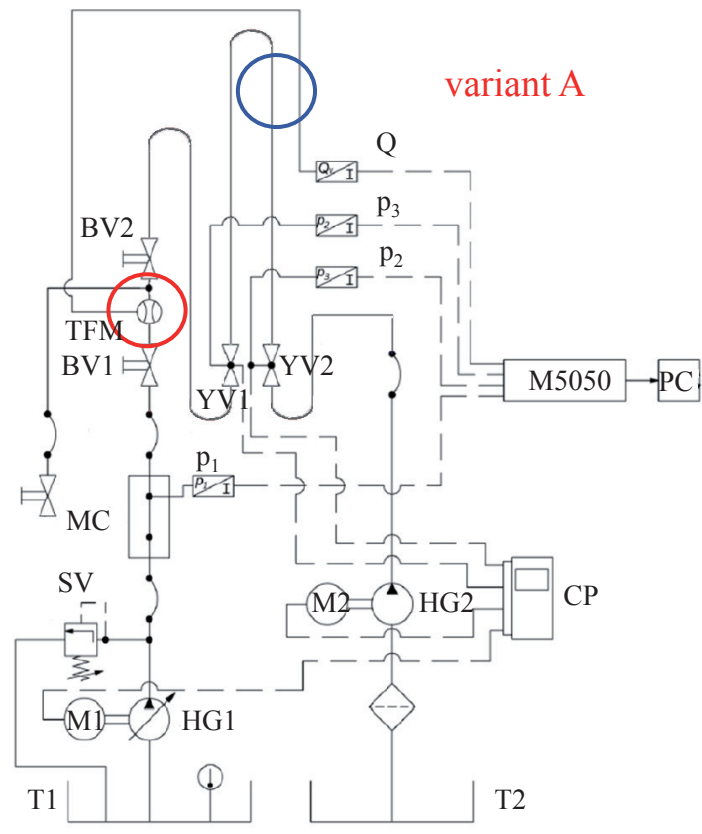

Fig. 2: Circuit diagram for measuring of hydraulics hammer.

with pressure sensors $p_{2}$ and $p_{3}$. Between valves YV1 and YV2 there is the clamp-on flowmeter CFM located, see variant B. The end of the horizontal pipeline is connected to a rubber hose leading to tank T2. This tank serves only as a fluid collection. Hydro-generator HG2 serves only to pump the liquid from tank T2 to tank T1. The valves YV1 and YV2 and the hydro generators $H G 1$ and $H G 2$ are controlled by the control panel CP.

The signals from pressure sensors are recorded in the Hydrotechnik M5050. The measurement record is set to $10 \mathrm{~s}$ with the sampling frequency $1000 \mathrm{~Hz}$. The pressure sensors $p_{1}, p_{2}, p_{3}$ have a range $(0 \div 60)$ bar and an accuracy $\pm 0.5 \%$. The flow measured on toothed flowmeter is also recorded in the Hydrotechnik M5050. The toothed flowmeter has a range $(0.7 \div 70) \mathrm{dm}^{3} \cdot \mathrm{s}^{-1}$ and an accuracy $\pm 0.5 \%$. The bi-directional non-invasive ultrasonic flowmeter has range of flowrate, resp. velocity in range $(0.1 \div 20) \mathrm{m}^{-1}$ and accuracy is $\pm 3 \%$ for tube diameter $(13 \div 75) \mathrm{mm}$ at velocity greater $0.2 \mathrm{~m} . \mathrm{s}^{-1}$.

Flow control is performed by tilting the hydrogenerator plate. Hydro-generator parameters are: theoretical geometric volume $V_{g}=51.22 \mathrm{~cm}^{3}$, nominal flow $Q=63 \mathrm{dm}^{3} \cdot \mathrm{min}^{-1}$. The safety valve (two-stage, indirect controlled) is controlled by a

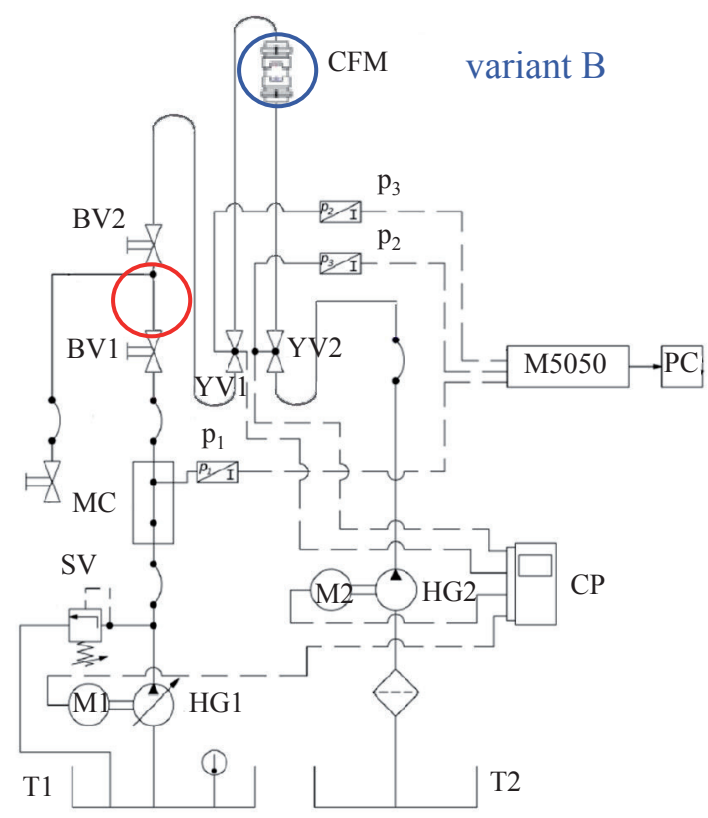

hand wheel.

The YV1, YV2 valves have a very fast response. Fig. 3 shows the shut-off time of the valve at given flow rate (for $Q_{A}=9.048 \mathrm{I}_{\mathrm{min}} \mathrm{min}^{-1}$ is $t_{u z}=59 \mathrm{~ms}$, for $Q_{B}=17.04$ I. $\mathrm{min}^{-1}$ is $t_{u z}=49 \mathrm{~ms}$ ).

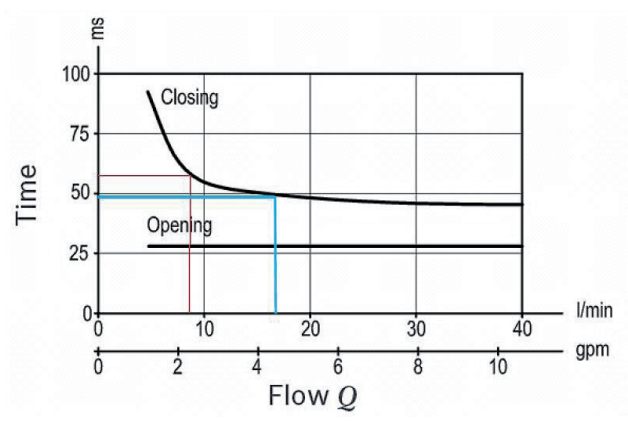

Fig. 3: Determination of shut-off time for YV1 and YV2. [1]

\section{Evaluation of the hydraulic hammer measurement by closing the valve YV1}

Measured pressure curves and period definitions needed to calculate fluid elasticity modulus $K$ in hydraulic hammer are presented in Fig. 4. To determine the sound velocity in the fluid, it is also necessary to know the distance between the pressure source and the closing point $(l=9.65 \mathrm{~m})$. 


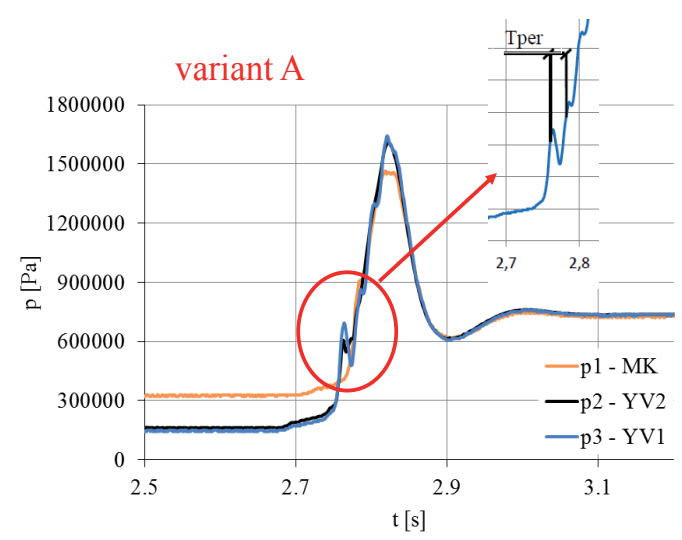

Fig. 4: Pressure curves at hydraulic hammer-variant $A, B$.

The mean values of steady state pressures are shown in Tab. 1. The pressure $p_{1}$ (variant A) measured on the measuring cube MK is higher by approximately $200 \mathrm{kPa}$ than the pressure $p_{1}$ (variant $\mathrm{B})$ measured in circuit with the toothed flowmeter. The pressures $p_{2}$ and $p_{3}$ (variant A) are measured on the valves and they are approximately about $100 \mathrm{kPa}$ higher at a double flow rate (variant B).

In Tab. 2 there are calculated basic parameters of hydraulic hammer, which are subsequently used for simulation.

Tab. 1: Average measured values of pressures and flow rate at steady state measured before closing of valve.

\begin{tabular}{|c|c|c|c|}
\hline & & Variant A & Variant B \\
\hline $\begin{array}{l}\text { Pressure on } \\
\text { measuring cube }\end{array}$ & $p_{1}(\mathrm{kPa})$ & 327 & 532 \\
\hline Pressure on valve YV1 & $p_{2}(\mathrm{kPa})$ & 162 & 265 \\
\hline Pressure on valve YV2 & $p_{3}(\mathrm{kPa})$ & 147 & 236 \\
\hline Flow rate & $Q\left(\mathrm{~m} 3 . \mathrm{s}^{-1}\right)$ & 0.00015 & 0.00028 \\
\hline
\end{tabular}

Tab. 2: Calculation of basic parameters of hydraulic hammer.

\begin{tabular}{|c|c|c|c|}
\hline & & Variant A & Variant B \\
\hline Period & $T_{p e r}(s)$ & 0.023 & 0.021 \\
\hline Wave run time & $T_{b v}(s)$ & 0.015 & 0.0105 \\
\hline $\begin{array}{l}\text { Speed of the sound } \\
\text { in the liquid }\end{array}$ & $a_{s}\left(m \cdot s^{-1}\right)$ & 1678.3 & 1838.1 \\
\hline Flow velocity & $v\left(m \cdot s^{-1}\right)$ & 0.48 & 0.9 \\
\hline $\begin{array}{l}\text { Modulus of fluid } \\
\text { elasticity }\end{array}$ & $K(\mathrm{kPa})$ & $2.45 \cdot 10^{6}$ & $2.94 \cdot 10^{6}$ \\
\hline Reynolds number & $\operatorname{Re}(1)$ & 126 & 237 \\
\hline
\end{tabular}

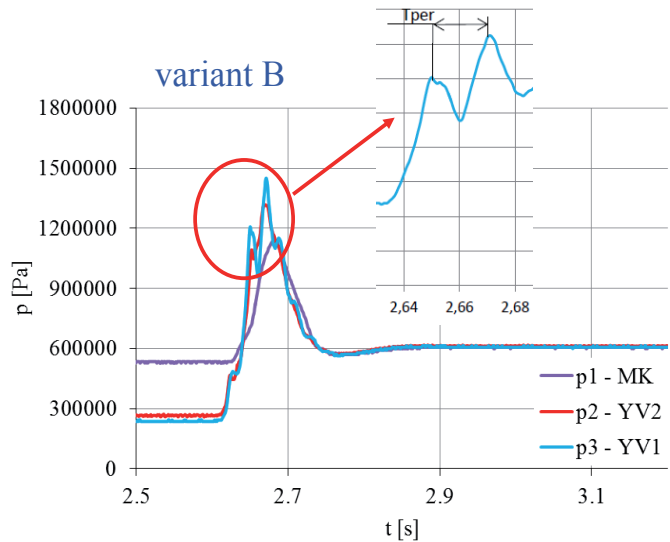

\section{Mathematical model of hydraulic circuit}

The mathematical model of the hydraulic circuit for hydraulic hammer measuring was created in the Matlab - Simulink program, using the SimHydraulics library, see Fig. 5.

Block of variable orifice represents valves YV1 and YV2, which is specified by parameterization of maximum flow area and opening. For this parameterization, it is only necessary to calculate the maximum flow area of the valve $S_{\max }=3.15 \cdot 10^{-4} \mathrm{~m}^{2}$ and estimate the flow coefficient see Tab. 3.

Tab. 3: Flow coefficient of valves YV1 YV2 for individual variants.

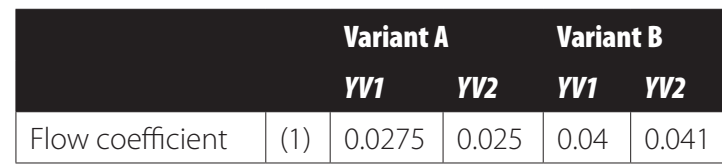

\section{Conclusions - Evaluation and comparison of simulation of hydraulic hammer with measurement}

The article deals with simulation of hydraulic hammer in oil flow at relatively low pressure (low pressure hydraulic system). Dynamics of flow is significantly influenced by the fluid elasticity modulus (oil), therefore it is necessary to deal with its precise determination depending on the pressure. Mathematical models of dynamic behaviour of flow were time-dependent, one-dimensional, solved in Matlab SimHydraulics. Two variants of the hydraulic circuit were tested. In Variant A, a toothed flowmeter (local resistance) was connected to the circuit. In variant $B$, the toothed flowmeter was replaced by a pipeline, and the flow was measured by an ultrasonic flowmeter that does not exhibit any 


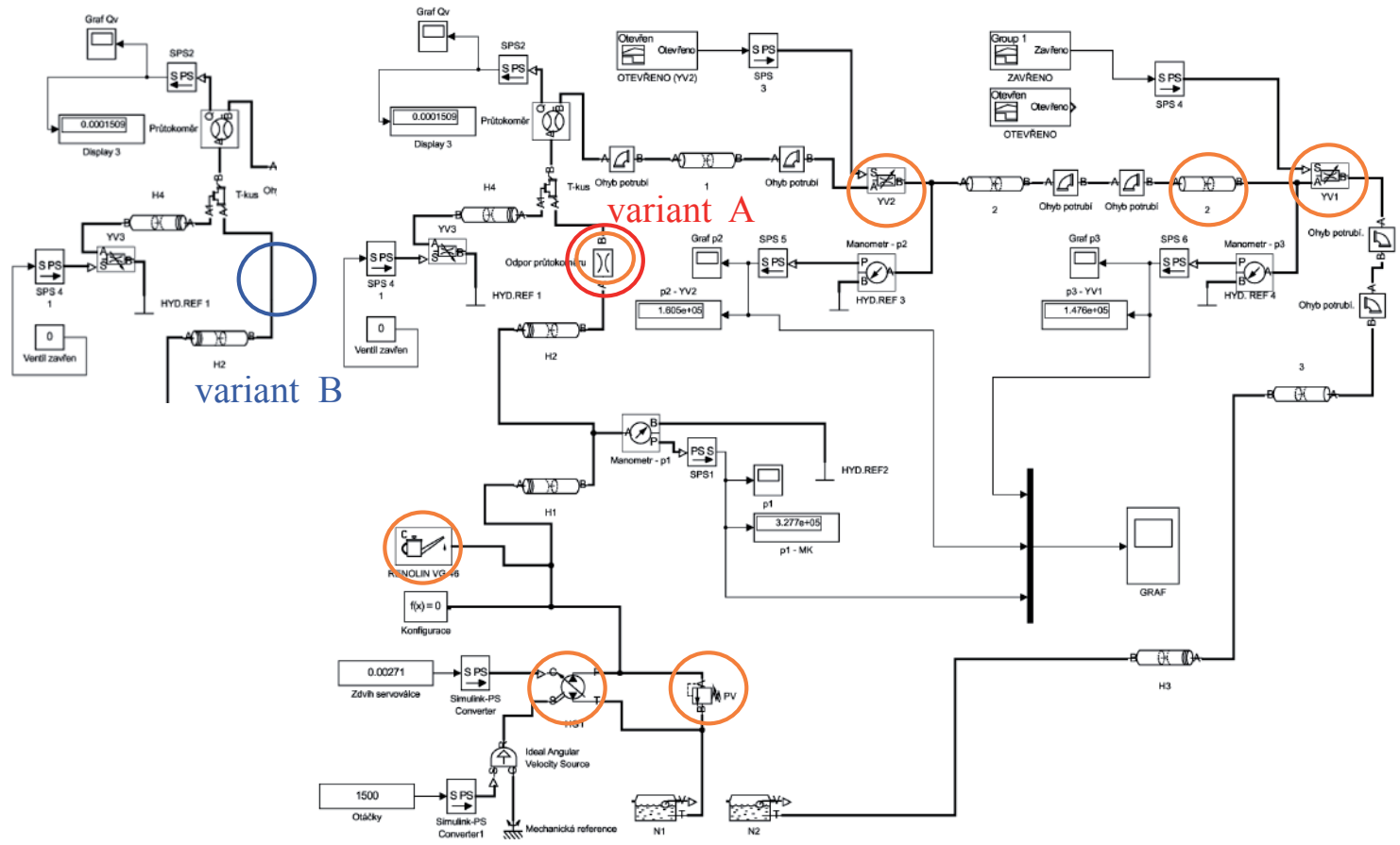

Fig. 5: Mathematical model of the circuit for the hydraulic hammer measurement (red - variant A, blue - variant B, orange-elements further specified).
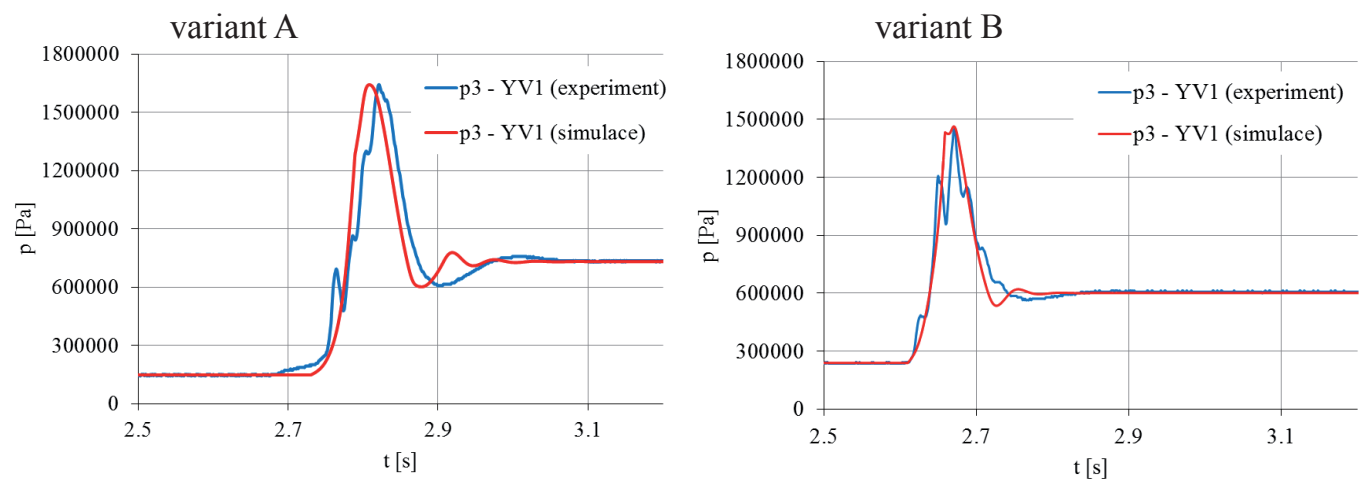

Fig. 6: Comparison of hydraulic hammer simulation with measurement.

resistance in the pipeline.

The modeled pressure curves for both variants (A, B) have approximately the same pressure peaks in simulation and measurement. For both variants, the simulated pressure curves are much smoother than measured. They differ slightly in the period (simulation period is smaller than the measured one).

In conclusion, one-dimensional simulation modeling (Matlab SimHydraulics) is well suited to measurement. The one-dimensional modeling method is relatively simple. All constants can be determined from the catalog sheets of individual hydraulic elements, or supplemented by measurement of static characteristics. The oil properties (density, modulus of fluid elasticity and kinematic viscosity) can be determined at a given temperature and pressure. In the article the 
modulus of fluid elasticity is determined from the measurement and other quantities from literature [6, 10]. For the two-stage indirect-controlled reduction valve (safety valve), it is necessary to consider the dynamics of the valve spool movement. Method of mathematical modeling allows you to simulate the dynamics of newly designed hydraulic circuits.

\section{Acknowledgment}

The work presented in this paper was supported by a grant SGS "Výzkum v oblasti dynamiky tekutinových systémü." SP2017/103.

\section{References and Notes}

[1] Puczok, P. (2017) Dynamic Behavior of Flow in Pipeline with Oil. Thesis. Ostrava.

[2] Noskievič J. (1995) Dynamics of fluid mechanisms. VŠB - TU Ostrava, Ostrava, ISBN 80-7078-297-8.

[3] Kozubková M. (2009) Mathematical models of cavitation and hydraulic hammer. VŠB - TU Ostrava, Ostrava, $130 \mathrm{~s}$. ISBN 978-80-248-2043-9.

[4] Jablonská J. (2014) Compressibility of the fluid. In EPJ Web of Conferences. EDP Sciences. Vol. 67, p. 02048.

[5] Brennen, E. (1995). Cavitation and bubble dynamics. Cambridge University Press.

[6] Hružík, L., Vašina, M., Bureček, A. (2013) Evaluation of Bulk Modulus of Oil System with Hydraulic Line. EPJ Web of Conferences. 45, 01041

[7] Dvořák, L. (2010) Fluid properties [online]. Ostrava: VŠB-TU Ostrava, 2010. http://www.338.vsb.cz/wp-content/uploads/2016/03/Dvorak-vlastnosti-tekutin.pdf

[8] Will, D., Gebhardt, N. (2008) Hydraulik Grundlagen, Komponenten, Schaltungen. Berlin; Heidelberg; New York: Springer, 4. edit., 450 s. ISBN 978-3-540-79534-6.

[9] Zymák, V. (1994) Dynamics of pulsating flow. Brno, $210 \mathrm{~s}$. ISBN 80-85895-00-5.

[10] MATLAB SimHydraulics, [online]. 2017. http://www.mathworks.com/help/index.html

\section{Biographical notes}

Jana Jablonská, Ing., PhD.: (1978) She is graduate of Faculty of Mechanical Engineering, VŠB-Technical University of Ostrava. The research is concentrated on multiphase mathematical modeling of static and dynamic phenomena in fluid flow especially hydraulic hammer and cavitation. 